\title{
MÉXICO: ¿ACTOR CON RESPONSABILIDAD MULTILATERAL?
}

\author{
MEXICO: AN ACTOR WITH MULTILATERAL \\ RESPONSIBILITY?
}

LE MEXIQUE EST-IL UN ACTEUR AUX
RESPONSABILITÉS MULTILATERALES?

\author{
Ana Covarrubias Velasco \\ El Colegio de México \\ ancova@colmex.mx
}

\begin{abstract}
Resumen: el artículo analiza la participación del gobierno mexicano en distintas iniciativas en la ONU y la OEA. Después de un breve resumen sobre las características más destacadas del multilateralismo, el trabajo examina la actividad de México en la onU en varios temas para influir en la gobernanza mundial en congruencia con el objetivo de hacer de México un actor con responsabilidad global. Posteriormente, aborda la política de México respecto del Grupo de Investigadores Expertos Independientes en el país y el caso de Venezuela en la OEA. Demuestra cómo la defensa de valores como la democracia y los derechos humanos inciden directamente en el escenario interno, provocando críticas a la política exterior e interior del gobierno mexicano.
\end{abstract}

Palabras clave: México; política exterior; multilateralismo; gobernanza; organizaciones internacionales.

Aвstract: The article analyzes the participation of the Mexican government in different initiatives in the UN and the OAS. After a brief summary of the most salient features of multilateralism, the paper examines Mexico's activity at the UN on a number issues that influence global governance, consistent with the goal of making Mexico an actor with global responsibility. Subsequently, it addresses Mexico's policy regarding the Group of Independent Expert Investigators in the country, and the case of Venezuela, at the OAS. It demonstrates how the defense of values such as democracy and human rights directly affect the internal scenario, provoking criticism of the foreign and domestic policy of the Mexican government. 
Keywords: Mexico; foreign policy; multilateralism; governance; international organizations.

\section{Traducción de Gonzalo Celorio Morayta}

Résumé: L'article analyse la participation du gouvernement de Peña Nieto à certaines initiatives de l'ONU et de l'OEA. Il esquisse d'abord les traits essentiels du multilatéralisme, puis il examine les activités qu'a menées le Mexique au sein de l'ONU dans l'espoir d'influencer la gouvernance mondiale, en accord avec son objectif de devenir un acteur aux responsabilités internationales. L'article traite ensuite de la politique du Mexique envers le Groupe interdisciplinaire d'experts indépendants dans son propre territoire, ainsi que de l'attitude mexicaine à l'OEA face au Venezuela. L'action en faveur de la démocratie et des droits de l'homme semble avoir eu des effets sur le plan national, où elle a suscité des critiques contre la politique du Mexique, aussi bien l'étrangère que l'interne.

Mots clefs: Mexique; politique étrangère; multilatéralisme; gouvernance; organismes internationaux.

Traducción de BERNARdo Mabire

Fecha de recepción: diciembre de 2018

Fecha de aceptación: febrero de 2019 


\section{L}

A frase clave de la política exterior del gobierno de Enrique Peña Nieto fue: "México: actor con responsabilidad global”. Pero, ¿por qué México se adjudica una responsabilidad global? ¿Ante qué tipos de sucesos internacionales debe ser responsable México? Las respuestas pueden ser múltiples y podría incluso argüirse que no hay necesidad de que México asuma una responsabilidad global. Detrás de esa propuesta, sin embargo, podemos encontrar una tendencia presente en la política exterior de México desde el 2000: el deseo vehemente de que se le reconozca como "alguien importante" en el sistema internacional, estatus justificado por las dimensiones del país, su demografía, ubicación geográfica, el tamaño de su economía, etcétera. Uno de los escenarios privilegiados para ejercer actividad global es el multilateral, ámbito que sirvió a la administración de Peña Nieto para mostrar un México que quiso influir en la política internacional.

Este artículo analiza algunas de las actividades de México en la Organización de las Naciones Unidas (ONU) y la Organización de los Estados Americanos (oEA), arguyendo que, en congruencia con una visión de sociedad internacional à la Hedley Bull, el gobierno mexicano actuó promoviendo normas, reglas y valores tratando de moldear la gobernanza mundial y regional al concebirse como un jugador global.

El trabajo está dividido en tres secciones: la primera examina brevemente las definiciones de sociedad internacional y multilateralismo, subrayando la primacía de las normas, reglas, instituciones y valores. La segunda parte trata algunas de las actividades más visibles de México en la onU, demostrando que México defendió el valor de la paz y contribuyó al establecimiento de regímenes. En tercer lugar, el artículo analiza las consecuencias de la política mexicana en la organización regional en temas como la democracia y los derechos humanos. Se estudia cómo el multilateralismo "entra en casa”. Finalmente, las conclusiones cuestionan la eficacia de la diplomacia mexicana así como la congruencia entre política interna y exterior. 


\section{El MUlTilateralismo EN UNA NUEZ}

En su famoso libro, The Anarchical Society, Hedley Bull propone la idea de sociedad internacional, que supone la existencia de normas e instituciones que los Estados comparten. Los Estados están conscientes de que hay ciertos intereses y valores comunes, se conciben vinculados por reglas que rigen sus relaciones, y trabajan por crear y defender instituciones como el derecho internacional, la diplomacia y las organizaciones internacionales. ${ }^{1}$ Así pues, la sociedad internacional cuenta con ciertas metas elementales: la preservación de la sociedad misma, el mantenimiento de la independencia y la soberanía externa de los Estados, la paz, la limitación de la violencia, el cumplimiento de las promesas y el respeto a la propiedad. ${ }^{2}$

El multilateralismo, basado en el derecho internacional y la diplomacia, puede verse como ilustración de la existencia de una sociedad internacional pues requiere que los Estados se comporten según ciertas normas y respeten las instituciones internacionales. ${ }^{3}$ Robert Keohane ha definido el multilateralismo como la práctica de coordinar políticas nacionales en grupos de tres o más Estados, mediante arreglos ad hoc o instituciones. Diebold, sin embargo, arguye que la esencia del multilateralismo no es el número de países participantes, sino el tipo de vínculos que se instituyen entre ellos; lo que distingue al multilateralismo es que las relaciones entre Estados se ordenan según ciertos principios. ${ }^{4}$ Para Atsushi Tago,

${ }^{1}$ Hedley Bull, The Anarchical Society. A Study of Order in World Politics, $3^{\text {a }}$. ed., Londres, Palgrave, 2002, p. 13. Énfasis añadido.

${ }^{2}$ Ibid., p. 18.

3 Atsushi Tago, "Multilateralism, Bilateralism, and Unilateralism in Foreign Policy", Oxford Research Encyclopedia of Politics, doi: 10.1093/acrefore/9780190228637.013.449

${ }^{4}$ Robert O. Keohane, "Multilateralism: An Agenda for Research", International Journal, vol. 45, núm. 4 (otoño de 1990), p. 731. Diebold citado por John Gerard Ruggie, "Multilateralism: the Anatomy of an Institution", International Organization, vol. 46, núm. 3 (verano de 1992), pp. 566-567. 
el "multilateralismo diplomático" se interesa por la manera en que la sociedad internacional o alguna institución aprueba una política; es decir, la práctica multilateral prohíbe ciertos actos y autoriza otros. Su objetivo fundamental es la cooperación, para lo cual puede imponer restricciones. En general, los Estados que buscan legitimidad, compartir costos, información o evitar la politización de sus actos recurrirán a ese tipo de política. ${ }^{5}$

Las instituciones multilaterales se crean para resolver problemas que exigen la colaboración de los Estados, para lo cual se determinan reglas y derechos. La organización internacional monitorea y maneja esas reglas, reduciendo la incertidumbre y los costos para sus miembros. ${ }^{6}$ Es decir, el multilateralismo y las organizaciones multilaterales en particular hacen previsible el comportamiento de los Estados, lo cual es necesario en los cálculos políticos de cada uno de ellos.

El multilateralismo enfrenta siempre grandes desafíos pues los Estados pueden obtener más ventajas al actuar de manera bilateral o unilateral. El siglo xxi ha sido testigo de una etapa muy difícil para el ámbito multilateral, especialmente desde la llegada de Donald Trump a la presidencia de Estados Unidos. Mucho se discute hoy la vigencia del liberalismo en el escenario internacional y de la vía multilateral cuando Estados Unidos y Reino Unido, los arquitectos del sistema, parecen no estar interesados en mantenerlo, y cuando China y Rusia también lo desafían. ${ }^{7}$ La actuación de China, según Tago, ha sido ambivalente, pues ha construido regímenes al tiempo que amenaza y debilita otros. Al igual que Rusia, China respeta el multilateralismo sólo cuando la opción bila-

5 Tago, art. cit.

${ }^{6}$ Keohane, "Multilateralism", op. cit., p. 759; 744.

7 Wolf Grabendorff, "El impacto de la globalización sobre el peso geopolítico del eje transatlántico en el orden internacional” y Alberto Hutschenreuter, “¿Crisis del atlantismo y del orden liberal internacional?”, ambos en Andrés Serbin (ed.), América Latina y el Caribe frente a un Nuevo Orden Mundial: poder, globalización y respuestas regionales, Barcelona y Buenos Aires, Icaria-CRIES, 2018, pp. 153-168 y 169-184; Tago, art. cit. 
teral o unilateral no es conveniente. El unilateralismo parece tener primacía. ${ }^{8}$

Es en este entorno de incertidumbre en el que México defiende el multilateralismo como la mejor alternativa para resolver problemas comunes; crea normas, principios y prácticas que se convierten en regímenes internacionales, pretende moderar la actuación unilateral de los Estados y es profundamente democrático, pues permite la actuación y el encuentro entre Estados pequeños, medianos y grandes. De este modo, la práctica multilateral es el instrumento por excelencia de países como México, interesados en promover un mundo de normas, certeza jurídica y política. ${ }^{9}$

EL ESCENARIO MUNDIAL: INTERESES Y GOBERNANZA INTERNACIONAL

Durante el sexenio de Peña Nieto, México fue muy activo en la ONU para influir en el diseño de reglas del juego en temas de su interés y para defender la paz. Actuó de manera congruente con su objetivo de ser actor global, aunque la eficacia de los regímenes creados pueda ponerse en duda. Esta sección analizará la defensa de la paz mediante la participación de México en las Operaciones para el Mantenimiento de la Paz (OMP) y el Tratado sobre Prohibición de las Armas Nucleares, y la creación de regímenes mediante la Agenda 2030, el cambio climático, el problema de las drogas y la migración.

Una de las decisiones más convincentes del gobierno para hacer de México un actor con responsabilidad global fue la decisión de participar en las omp. La colaboración de México en ese tipo de misiones se venía discutiendo desde la administración del presidente Vicente Fox pero diferencias entre las

8 Tago, loc. cit.

${ }^{9}$ Miguel Ruiz Cabañas Izquierdo y María Paulina Rivera Chávez, "En defensa del multilateralismo", Revista Mexicana de Política Exterior, núm. 110 (mayo-agosto de 2017), p. 11. 
fuerzas políticas internas lo habían hecho imposible. En 2013, Peña Nieto instruyó la creación del Grupo Intersecretarial de Trabajo, que incluía a los secretarios de Relaciones Exteriores, Defensa y Marina Armada de México, para que evaluara la conveniencia y posibilidad de que el país reanudara su actividad en las OMP. La decisión a favor se justificó con la consideración de que México podría contribuir directamente a la paz y seguridad internacionales, y cumpliría con las expectativas de algunos países que durante varios años habían esperado -y solicitado- un México comprometido con los retos globales. ${ }^{10}$ México obtendría una de las credenciales fundamentales para ser reconocido como actor con responsabilidad global y podría ampliar su presencia en regiones en donde tenía poca o nula influencia, como África y el Medio Oriente, e incrementar su capacidad de interlocución con las potencias, los países en conflicto, sus vecinos y otros contribuyentes con tropas. ${ }^{11}$ Además, la participación de México lo colocaría en mejor posición para contar con un asiento no permanente en el Consejo de Seguridad con regularidad.

La participación en las OMP ha sido gradual: comenzó con el envío de personal a lugares estratégicos para la política exterior y con bajo riesgo militar y sanitario. Asimismo, los primeros destinos se escogieron con el fin de brindar a las fuerzas armadas la oportunidad del aprendizaje y de integrarse en contingentes que contaran con representación de países iberoamericanos para poder estrechar vínculos de cooperación con sus fuerzas armadas. Las tareas a realizar han sido de naturaleza humanitaria y no se ha enviado personal combatiente. ${ }^{12}$

La cancillería y las Fuerzas Armadas de México diseñaron una hoja de ruta para incorporar a los efectivos militares entre 2015 y 2020. Los requisitos para la participación mexi-

10 Ana Paola Barbosa, "La política exterior de México en las omP", México, Secretaría de Marina, Instituto de Investigaciones Estratégicas de la Armada de México, 2015.

${ }^{11}$ Loc. cit. 
cana han sido: contar siempre con la autorización expresa y el mandato del Consejo de Seguridad así como con el consentimiento expreso y la cooperación del Estado en donde se despliega la operación; regirse por el marco jurídico nacional y las prioridades de la política exterior y dedicarse a tareas de índole humanitaria en beneficio de la población. ${ }^{13}$ Hacia el final del sexenio, la Secretaría de Relaciones Exteriores (SRE) informaba que de marzo de 2015 a junio de 2018 se habían realizado 72 despliegues de personal de las Fuerzas Armadas y de la Comisión Nacional de Seguridad en ocho operaciones de paz en el Sahara Occidental, Líbano, Haití, República Centroafricana y Malí, así como en la Misión Especial en Colombia para monitorear y verificar el Acuerdo Final de Paz entre el gobierno y las Fuerzas Armadas Revolucionarias de Colombia-Ejército del Pueblo. ${ }^{14}$

El valor de la paz no sería defendido únicamente mediante las OMP; congruente con su tradición, México participó activamente en el proceso que concluyó con el Tratado sobre la Prohibición de las Armas Nucleares, ratificado en enero de 2018. Podría cuestionarse el valor de la actuación mexicana para la conclusión de este tratado si se tiene en cuenta que México no posee armas nucleares, ni el deseo ni la capacidad para tenerlas, y tampoco ejerce poder de influencia en los países que sí las tienen. Aun así, podría argumentarse que la no proliferación de ese tipo de armas y su eventual destrucción conviene al interés de México al asegurar un escenario internacional menos peligroso.

México favoreció una convención única que incluyera disposiciones en materia de prohibición, destrucción, eliminación y verificación, buscando siempre la estigmatización de las armas nucleares. ${ }^{15}$ Esto último se logró mediante la

13 México, Secretaría de Relaciones Exteriores, Tercer Informe de Labores, 2014-2015, p. 121.

${ }^{14}$ Luis Videgaray Caso, "Presentación”, Sexto Informe de Labores, 2017 2018, México, Secretaría de Relaciones Exteriores, 2018.

15 Jorge Lomónaco, "Hacia la prohibición de las armas nucleares", Revista Mexicana de Política Exterior, núm 110 (mayo-agosto de 2017), p. 86. 
resolución 70/50, de 2015, que presentó junto con Austria, Irlanda y Sudáfrica. Con base en un cambio doctrinario promovido por el papa Francisco, la resolución "Imperativos éticos para un mundo libre de armas nucleares" calificó a ese tipo de armas como inherentemente inmorales. ${ }^{16}$ A partir de ese momento, se establecieron dos grupos de trabajo en la Asamblea General, con participación de México y Austria, para evaluar los avances en las negociaciones multilaterales de desarme nuclear. Esos grupos sesionaron en 2013 y 2016 , y recomendaron a la Asamblea convocar a una conferencia en 2017. ${ }^{17}$ El tratado que resultó de ésta no eliminó ojivas nucleares y no es obligatorio para los poseedores de armas nucleares que decidan vincularse al régimen. Es decir, sólo quienes tienen armas nucleares pueden decidir eliminarlas, por lo que no afecta sus políticas de seguridad o disuasión. Por otra parte, quienes no poseen ese tipo de armas asumen obligaciones de no proliferación adicionales a las adquiridas en el Tratado de No Proliferación (TNP) y pueden formar parte de zonas libres de armas nucleares. Las nuevas obligaciones no sustituirían a las anteriores de forma tal que el Tratado de prohibición de armas nucleares es congruente con el TNP y se convierte en medida definitiva de no proliferación. ${ }^{18}$ México, según Jorge Lomónaco, desempeñó un papel determinante en este proceso, "proporcional a su tamaño e influencia global". ${ }^{19}$

Otros temas en los que México intentó influir en el diseño de la gobernanza global relacionados de manera más directa con sus intereses nacionales fueron el desarrollo sostenible, el cambio climático, las drogas y la migración. México apoyó con entusiasmo la Agenda 2030 para el Desarrollo Sostenible que busca, entre otras cosas, eliminar la pobreza y el hambre, reducir la desigualdad, brindar educación de

${ }^{16}$ Ibid., p. 88.

${ }^{17}$ Ibid., p. 89.

${ }^{18}$ Ibid., p. 91.

${ }^{19}$ Ibid., p. 95. 
calidad para todos, fomentar la equidad de género, cambiar los patrones de producción y consumo en favor de economías limpias y sustentables, y proteger el medioambiente y la biodiversidad. ${ }^{20}$ Así pues, el gobierno asumió los 17 objetivos y las 169 metas de la Agenda como compromiso de Estado y elabora una hoja de ruta para cumplir con ellos. ${ }^{21}$ México también organizó la Reunión de los Países de América Latina y el Caribe sobre Desarrollo Sostenible en 2017, que será el mecanismo de seguimiento de instrumentación de la Agenda en la región, y fue el primer país del mundo en cumplir con la revisión nacional voluntaria ante el Foro Político de Alto Nivel de la onU, el mecanismo global de seguimiento. ${ }^{22}$

En el caso del cambio climático, México adoptó el Acuerdo de París en 2015, y su contribución se remonta al proceso que inició en Cancún en 2010, cuando reencauzó la discusión sobre el tema y fortaleció la Convención Marco de Naciones Unidas para el Cambio Climático en la cop16-CMNUCC. El Acuerdo de París es jurídicamente vinculante e intenta mejorar la respuesta de la comunidad internacional al cambio climático. ${ }^{23}$

Las drogas y la migración son asuntos graves y cotidianos en México, por lo que no sorprende el deseo del gobierno de contar con normas y reglas para enfrentarlos. Con el propósito de cambiar el enfoque prohibicionista y punitivo que había dominado la cuestión de las drogas, México, Guatemala y Colombia convocaron a un periodo extraordinario de sesiones de la Asamblea General en 2012. La estrategia dominante ha responsabilizado a los países productores y de tránsito, y no tanto a los consumidores, y ha descansado en las políticas de seguridad como el instrumento para tratar de solucio-

${ }^{20}$ Ruiz Cabañas Izquierdo y Rivera Chávez, "En defensa del multilateralismo", art. cit., pp. 17-18.

${ }^{21}$ Miguel Ruiz Cabañas Izquierdo en Cuarto Informe de Labores 2015 2016, México, sRe, p. 119.

${ }^{22}$ Ruiz Cabañas Izquierdo y Rivera Chávez, art. cit., p. 18.

23 Ibid., p. 19. 
nar el problema. ${ }^{24}$ La evidencia, sin embargo, sugiere que el consumo de drogas ha aumentado al ritmo del crecimiento de la población, y la edad de inicio de consumo de drogas se ha reducido, acercando a los adolescentes a la adicción. Más aún, las organizaciones criminales no han variado sus rutas y modo de operación, y sus actividades delictivas se han extendido a áreas como el lavado de activos, el tráfico ilícito de armas, la extorsión y la trata de personas. Finalmente, se han producido 500 nuevas sustancias psicoactivas disponibles en el mercado. ${ }^{25}$

Según Isaac Morales, los retos que México enfrenta como país de producción, tránsito y consumo le daban autoridad y legitimidad para solicitar la cooperación internacional. La sesión extraordinaria, conocida como UNGASS (Special Session of the United Nations General Assembly on the World Drug Problem) tuvo lugar en 2016, y el papel de México en las negociaciones fue muy destacado, buscando tender puentes y lograr convergencias entre países. La UNGASs adoptó la resolución "Nuestro compromiso conjunto de abordar y contrarrestar eficazmente el problema mundial de las drogas" como lineamiento para lograr mayor integralidad en las políticas sobre drogas y responder de manera más equilibrada a la compleja dinámica del fenómeno. Hubo consenso en el sentido de que el enfoque punitivo no era suficiente y se cambiaron los términos de referencia del debate sobre las drogas. ${ }^{26}$

Peña Nieto participó en la UNGAss y subrayó la necesidad de adoptar una perspectiva de derechos humanos, prevención y salud pública, que pusiera en el centro el bienestar de las personas y que combatiera a los delincuentes sin criminalizar a los consumidores. Asimismo, los países consumidores deberían asumir un mayor compromiso en la reducción de la demanda y en el combate al crimen organizado transna-

${ }^{24}$ G. Isaac Morales Tenorio, "Estrategia multilateral de México frente al problema de las drogas: del diagnóstico a la acción”, Revista Mexicana de Política Exterior, núm. 110 (mayo-agosto de 2017), p. 138.

${ }^{25}$ Ibid., pp. 140-141.

${ }^{26}$ Ibid., pp. 147-148. 
cional. El presidente resumió la posición de México en diez puntos, entre los que destacan: atender los daños sociales relacionados con el mercado ilícito de drogas; favorecer penas proporcionales y alternativas al encarcelamiento y sumar esfuerzos internacionales para prevenir el consumo mediante campañas orientadas a niños y jóvenes. ${ }^{27}$ La Resolución final incluye siete recomendaciones basadas en las propuestas que promovió México, pero no otras como la abolición de la pena de muerte para delitos relacionados con las drogas o la mención explícita a la despenalización del consumo de drogas. ${ }^{28}$ Aun así, el gobierno consideró a la UNGAss como un triunfo diplomático.

Otro logro de política exterior según el gobierno fue el papel de México en la conclusión del Pacto Mundial para la Migración Segura, Ordenada y Regular (PMM) en 2018. El proceso que llevó al Pacto empezó en 2016, con la Declaración de Nueva York, y fue coordinado por los representantes ante Naciones Unidas de México y Suiza, Juan José Gómez Camacho y Jürg Lauber, respectivamente. México propuso acordar un texto basado en la gobernanza de las migraciones que ubicara a las personas en el centro del mismo, poniendo énfasis en el respeto a los derechos humanos independientemente de su situación migratoria y en el reconocimiento de la migración como fuente de prosperidad e innovación y desarrollo sostenible en los países de origen y destino. Además, las causas estructurales de la migración debían ser atendidas desde una visión de responsabilidad compartida. ${ }^{29}$ México

${ }^{27}$ Enrique Peña Nieto, "Discurso del Presidente de México, Enrique Peña Nieto, durante la Sesión Especial de la Asamblea General sobre el problema mundial de las drogas (UNGAss) 2016”, 19 de abril de 2016, https://www.gob.mx/cms/uploads/attachment/file/210802/7. PEUM-_UNGASS_2016.pdf (consultado el 2 de noviembre de 2011).

28 Morales Tenorio, "Estrategia Multilateral de México frente al problema de las drogas”, art. cit., pp. 147-148.

${ }^{29}$ Secretaría de Relaciones Exteriores (SRE), Embajada de México en Santa Sede, "México reafirma su compromiso con el multilateralismo y con la gobernanza efectiva de la migración internacional" (comunicado 
participó en las tres fases preparatorias del PMм y fue sede de la reunión de balance, hito en el proceso previo al inicio de las negociaciones formales. ${ }^{30}$ El Pacto fue adoptado a finales de 2018 y no es jurídicamente vinculante.

No hay necesidad de reiterar el deseo del gobierno mexicano de influir en la gobernanza mundial en los temas analizados. Sin embargo, no está de más preguntarse sobre la eficacia de la actividad de México así como de las consecuencias internas de esa política. ¿Vale la pena seguir una estrategia como la que siguió México si algunos de los tratados no son vinculantes y, sobre todo, si países como Estados Unidos no son parte de éstos? Los ejemplos del Acuerdo de París y el PMM son pertinentes: ¿ha sido útil el trabajo de México cuando la gran potencia no se siente vinculada por esas normas y reglas? ¿Sirve así al interés nacional? Es probable que toda esta actividad no contribuya directamente a resolver los problemas nacionales. Además, el multilateralismo mexicano está muy lejano de la opinión pública, por lo que no hay un reconocimiento significativo en México de lo que se hace afuera. Entonces, ¿por qué lo hace México?

En primer lugar, por congruencia con el objetivo del gobierno de ser un jugador global: México gana influencia internacional y prestigio. Asimismo, no es extraño que un país de la magnitud de México quiera establecer las reglas del juego del cual participa. Por otro lado, podría argüirse que la política exterior tiene su propia lógica: es eso lo que hace la política exterior. Puede, ciertamente, no hacerse, pero en el caso del gobierno de Peña Nieto coincidió con la voluntad política de actuar. La eficacia de lo logrado depende de muchas variables fuera del control del país, pero la política exterior hizo su trabajo.

de prensa), 13 de julio de 2018, https://embamex.sre.gob.mx/vaticano/ index.php/noticias/256-mexico-en-el-pacto-mundial-para-una-migracion-segura-ordenada-y-regular (consultado el 2 de noviembre de 2018).

30 Loc. cit. y Secretaría de Relaciones Exteriores, SRE, Sexto Informe de Labores 2017-2018, p. 146 y la presentación de Miguel Ruiz Cabañas Izquierdo, subsecretario para Asuntos Multilaterales y Derechos Humanos. 


\section{El escenario RegionAl: El MULTilateralismo en MéXico}

La actividad en la onu fue bien recibida en el exterior y posiblemente el tema no interesó a la opinión pública en el país. Pero, ¿qué pasa cuando el multilateralismo toca valores problemáticos y "se mete" en casa? Esto sucedió en el escenario regional, que fue un ámbito mucho más complicado que el universal. México recurrió a la Comisión Interamericana de Derechos Humanos (CIDH) para solicitar ayuda en el caso de la desaparición de 43 estudiantes de la Escuela Normal Rural "Raúl Isidro Burgos" de Ayotzinapa, estado de Guerrero, y promovió la democracia en la oEA. En ambos casos, el gobierno consideró que la democracia y los derechos humanos eran valores universales que merecían ser defendidos en México y la región. La estrategia, sin embargo, no transcurrió sin fricciones y le mereció la crítica interna e internacional. En breve, el gobierno apoyó y cuestionó al mismo tiempo los mecanismos multilaterales, y la opinión pública y los gobiernos extranjeros cuestionaron, a su vez, la política mexicana.

El ejemplo más ilustrativo sobre el vínculo entre el apoyo al multilateralismo y la política interna fue el Grupo Interdisciplinario de Expertos Internacionales (GIEI) que coadyuvó a la investigación de los estudiantes desaparecidos en septiembre de 2014, cuando tomaron autobuses comerciales en Iguala, Guerrero, al parecer para dirigirse a la Ciudad de México. Se cree que los estudiantes fueron atacados por policías coludidos con el cartel criminal Guerreros Unidos, y los entregaron a este último. ${ }^{31}$ A decir de The New York Times, el gobierno mexicano solicitó la ayuda de la CIDH por pre-

31 Washington Office on Latin America, wolA, "Un año después de la salida del GIEI de México: el caso de Ayotzinapa sigue sin resolverse y las desapariciones en México se mantienen en niveles preocupantes”, 21 de abril de 2017, https://www.wola.org/es/analisis/un-ano-despues-dela-salida-del-giei-de-mexico-el-caso-de-aytozinapa-sigue-sin-resolverse-ylas-desapariciones-en-mexico-se-mantienen-en-niveles-preocupantes / (consultado el 29 de noviembre de 2018). 
sión de Amnistía Internacional, la Organización de Naciones Unidas y los representantes de las familias de los $43 .{ }^{32}$ El GIEI fue resultado de un acuerdo firmado entre la CIDH, el Estado mexicano y el Centro de Derechos Humanos Miguel Agustín Pro Juárez que funge como representante de los 43 estudiantes y sus familias para colaborar con la investigación. Se firmó en noviembre de 2014 y los objetivos que establecía eran el seguimiento a la implementación de medidas cautelares otorgadas por la Comisión; es decir, dar con el paradero de los estudiantes, proteger la vida e integridad de los heridos, adoptar medidas para los beneficiarios y sus representantes, y elaborar informes sobre las acciones que se adoptaran para investigar los hechos. ${ }^{33}$

El trabajo del GIEI en México no fue fácil ni para el Grupo ni para el Estado mexicano. El Grupo se quejó de que el gobierno no le dio toda la evidencia que tenía sobre el caso ${ }^{34}$ y que las autoridades mexicanas habían hecho que su labor se dificultará más desde enero de 2016, cuando las diligencias, las respuestas a peticiones y la toma de declaraciones se hicieron mucho más lentas; hubo escaso interés en las nuevas líneas de investigación que proponía y no pudo investigar a funcionarios de alto nivel, especialmente del ejército, ni acceder a instalaciones clave. ${ }^{35}$

${ }^{32}$ Marina Franco, "El caso Ayotzinapa: Cuatro años de dolor e incertidumbre", The New York Times, 26 de septiembre de 2018, https: / /www.nyti mes.com/es/2018/09/26/ayotzinapa-estudiantes-43-mexico/ (consultado el 29 de noviembre de 2018).

33 Acuerdo para la incorporación de asistencia técnica internacional desde la perspectiva de los derechos humanos en la investigación de la desaparición forzada de 43 estudiantes de la normal rural Raúl Isidro Burgos de Ayotzinapa, Guerrero, dentro de las medidas cautelares $\mathrm{MC} / 409 / 14$ y en el marco de las facultades de monitoreo que la CIDH ejerce sobre la situación de los derechos humanos en la región, en Centro Prodh (sitio de internet), centroprodh.org.mx/GIEI/?page_id=19

34 wOLA, art. cit.

35 Alberto Nájar, "México: Expertos del caso Ayotzinapa se despiden y denuncian obstáculos en su investigación”, BBC Mundo, 24 de abril de 2016, https://www.bbc.com/mundo/noticias/2016/04/160424_ayotzina 
El desencuentro esencial, sin embargo, fue resultado de que el Grupo cuestionara la "verdad histórica" ofrecida por la Procuraduría General de la República (PGR) -respecto a que los estudiantes habían sido incinerados en el basurero de Cocula-, y propusiera nuevas líneas de investigación. El GIEI señaló que las autoridades habían manipulado evidencia, torturado a sospechosos y que no habían investigado pistas que podrían haber llevado a una conclusión distinta de la del basurero de Cocula. En esencia, el Grupo sugería que en uno de los autobuses secuestrado por los estudiantes había droga que el cartel Guerreros Unidos quiso recuperar. ${ }^{36}$ Finalmente, hubo un gran desacuerdo entre el Grupo y el gobierno mexicano respecto de la extensión del mandato del primero: las autoridades mexicanas se negaron a prorrogar seis meses más las labores del GIEI ${ }^{37}$ y no hubo representantes del gobierno de México en la presentación del último informe del Grupo.

El resultado de la presencia del GIEI en México fue el descrédito del gobierno ante muchos sectores de la opinión pública interna e internacional. El premio Nobel, Adolfo Pérez Esquivel, por ejemplo, declaró que en México se cometían crímenes de lesa humanidad y que la estrategia contra el crimen organizado era responsable de la crisis de inseguridad y las constantes violaciones a los derechos humanos en el país. ${ }^{38}$

pa_giei_informe_final_an, consultado el 29 de noviembre de 2018, y Franco, "El caso Ayotzinapa: Cuatro años de dolor e incertidumbre", art. cit.

36 Loc. cit.

37 Según Peña Nieto, el mandato del GIEI no sería prorrogado pues su duración había sido convenida y ya incluso se había ampliado en una ocasión. "Confirma Peña desde Copenhague el fin de la estancia del GIEI en México", La Jornada, 15 de abril de 2016, p. 5, http://www.jornada. unam.mx/2016/04/15/ppolitica/005n2pol, consultado el 15 de agosto de 2017.

38 Emir Olivares Alonso, "Lamenta Pérez Esquivel la impunidad en México ante crímenes de lesa humanidad", La Jornada, 15 de abril de 2016, http:/ / www.jornada.unam.mx/2016/04/15/politica/006n1pol (consultado el 15 de agosto de 2017). 
En breve, lo que el caso del GIEI demuestra es la disposición del Estado mexicano de recurrir a los mecanismos multilaterales en una situación que no pudo resolver solo y en el que necesitaba la legitimidad externa. Al mismo tiempo, sin embargo, los resultados del GIEI demuestran los límites de esa apertura y, paradójicamente, el cuestionamiento del Estado mexicano al instrumento multilateral. Así pues, las críticas se dieron en dos sentidos, de las autoridades mexicanas al GIEI, y de éste a las autoridades mexicanas. No fue un caso de éxito para ninguna de las dos partes y provocó críticas internas e internacionales al gobierno mexicano.

El caso de Venezuela en la oeA también demostró las consecuencias negativas de la política multilateral mexicana tanto en el país como en el exterior. ${ }^{39}$ La actividad de México en la organización regional empezó ante el agravamiento de la situación en Venezuela en 2017, particularmente tras el intento del Tribunal Superior de Justicia de asumir ciertas competencias que correspondían a la Asamblea Nacional y la convocatoria a elecciones para la Asamblea Constituyente. La posición de México a partir de entonces subrayaba la interrupción del orden democrático en ese país, por lo que procuró la adopción de resoluciones que llamaran a la negociación y la restauración de la institucionalidad y, en última instancia, la aplicación de la Carta Democrática Interamericana. ${ }^{40}$

Las gestiones mexicanas para lograr una resolución sobre Venezuela aumentaron notablemente hacia la 47 Asamblea General, celebrada en Cancún en junio de 2017. En esa ocasión se discutió un texto que pedía la creación de un grupo de contacto que actuara como árbitro entre el gobierno de Nicolás Maduro y la oposición, dejar sin efecto la convocatoria a la Asamblea Constituyente, liberar a los presos polí-

${ }^{39}$ Esta sección se basa en Ana Covarrubias, "La política de México hacia América Latina en el siglo xxI: ¿congruencia y legitimidad?”, en Estudios Internacionales, vol. 49 (2017), edición especial 50 años.

${ }^{40}$ Secretaría de Relaciones Exteriores, SRE, "Situación en Venezuela", comunicado núm. 252, https://www.gob.mx/sre/prensa/situacionen-venezuela?idiom=es (consulta del 31 de julio de 2017). 
ticos y establecer un cronograma electoral. Aunque a decir del Secretario de Relaciones Exteriores, Luis Videgaray, se contaba con los 23 votos necesarios para aprobarse, al final sólo 20 países votaron a favor. ${ }^{41}$ Ante este resultado, México reiteró su defensa de los valores democráticos: "tenemos la obligación política, moral y como Estado miembro de esta organización de seguir por la vía diplomática agotando todos los caminos". ${ }^{2}$ Para México la democracia representativa era "la única forma de gobierno admisible en el hemisferio americano" y los derechos humanos el "principio fundamental, constitucional de la política exterior mexicana”. ${ }^{43}$

La reacción venezolana fue muy dura; ya con anterioridad, la ministra de Relaciones Exteriores, Delcy Rodríguez, había afirmado que México no tenía la autoridad moral para descalificar a Venezuela al citar la desaparición de los 43 nor-

41 "La sorpresa vino por un lado de algunas naciones del Caribe, que hasta unas horas antes, incluso minutos antes habían, nos habían comunicado a través de nuestros Embajadores y el trabajo de las delegaciones que votarían a favor, en lo que movió en el número de votos a favor por el uso de información fue el cambio de última hora de algunas naciones..." Luis Videgaray, "Conferencia de prensa por la clausura del $47 \mathrm{Pe}$ riodo Ordinario de Sesiones de la AGOEA", 21 de junio de 2017, https:/ / www.gob.mx/sre/prensa/mensaje-del-canciller-luis-videgaray-en-la-conferencia-de-prensa-por-la-clausura-del-47-periodo-ordinario-de-sesionesde-la-agoea (consultado el 2 de noviembre de 2018).

${ }^{42}$ Luis Videgaray en "Declaración a medios y conferencia de prensa de Cancilleres en la 47 Asamblea General de la OEA", 19 de junio de 2017, https://www.gob.mx/sre/es/prensa/declaracion-a-medios-y-conferenciade-prensa-de-cancilleres-en-la-47-asamblea-general-de-la-oea?idiom=es (consultado el 2 de noviembre de 2018).

${ }^{43}$ Luis Videgaray, "Conferencia de prensa por la clausura del $47 \mathrm{Pe}-$ riodo Ordinario de Sesiones de la AGOEA”, art. cit. Según Peña Nieto, era indispensable preservar los valores compartidos, "el apego a las reglas y normas de la democracia, y en el marco de nuestras instituciones, ya sean nacionales, regionales o globales, para poder enfrentar los desafíos regionales". Alonso Urrutia, Georgina Saldierna y Blanche Pietrich, "Multilateralismo, el camino: Peña", La Jornada, 20 de junio de 2017, p. 4, http:// www.jornada.unam.mx/2017/06/20/politica/004n1 pol (consultado el 15 de agosto de 2017). 
malistas así como las numerosas ejecuciones de periodistas en el país. ${ }^{44}$ Durante la 47 Asamblea, Rodríguez presentó varias propuestas, una de las cuales llamaba a la solidaridad interamericana con "la exigencia de verdad, justicia y reparación" de las familias de los estudiantes desaparecidos y condenaba toda política estatal que, por acción u omisión hubiese promovido, propiciado o ejecutado la desaparición forzada o ejecuciones extrajudiciales como medio de control social o amedrentamiento de la población en desmedro de los derechos humanos. El texto se desechó por unanimidad pues no "era pertinente", según el representante de México, Luis Alfonso de Alba, ${ }^{45}$ pero Rodríguez y el diputado Julio Chávez, del Partido Socialista Unido de Venezuela, se reunieron con familiares de los estudiantes desaparecidos y los invitaron a su país para presenciar la convocatoria de la Asamblea Constituyente. ${ }^{46}$

En México, algunos académicos lamentaron que México apoyara la contrarrevolución; ${ }^{47}$ la Comisión Permanente del Congreso de la Unión pidió al gobierno cumplir con los principios normativos de la política exterior. Los senadores Dolores Padierna y Manuel Bartlett, del PRD y PT-Morena, respectivamente, exigieron respetar el principio de no inter-

${ }^{44}$ Blanche Pietrich y Georgina Saldierna, "Hoy, nueva embestida contra Maduro encabezada por EU", La Jornada, 19 de junio de 2017, http:/ / www.jornada.unam.mx/2017/06/19/politica/003n1pol (consultado el 15 de agosto de 2017). Énfasis añadido.

45 Georgina Saldierna y Blanche Pietrich, "Fracasa golpeteo contra Venezuela", La Jornada, 22 de junio de 2017, http://www.jornada.unam. mx/2017/06/22/politica/002n1pol, y Georgina Saldierna y Blanche Pietrich, "Caracas exige en la OEA verdad y justicia para el caso Ayotzinapa", La Jornada, 21 de junio de 2017, https://www.jornada.com.mx/2017/ 06/21/politica/003n1 pol (consultados el 15 de agosto de 2017). loc. cit.

46 "Caracas exige en la OEA verdad y justicia para el caso Ayotzinapa",

${ }^{47}$ Carolina Gómez Mena, "Un puñado de gobiernos derechistas busca aislar a Venezuela, afirman académicos", en La Jornada, 21 de junio de 2017, https://www.jornada.com.mx/2017/06/21/politica/004n2pol (consultado el 15 de agosto de 2017). 
vención en los conflictos de otras naciones. ${ }^{48}$ Padierna expresó su satisfacción porque no se hubiese aprobado la resolución promovida por el secretario Videgaray pues "[C]uestionan los procedimientos electorales en Venezuela, pero en México arrebatan la Presidencia de la República a cualquier costo. Cuestionan la violación de derechos humanos en el país hermano, pero justifican los más de 200000 muertos en los dos sexenios recientes". ${ }^{49}$

México no reconoció los resultados de las elecciones de los integrantes de la Asamblea Nacional Constituyente, lamentó que el gobierno venezolano hubiese llevado a cabo comicios "contrarios a los principios democráticos reconocidos universalmente" y que no se apegaban a la Constitución de Venezuela. La SRE reiteró el respeto de México a la soberanía venezolana e instó a todas las partes a establecer un diálogo "genuino y con garantías" que permitiera al pueblo de ese país restaurar el orden democrático. ${ }^{50}$ Finalmente, el gobierno mexicano suscribió la Declaración de Lima que, entre otras cosas, señalaba que Venezuela no era una democracia y que los actos emanados de la Asamblea Nacional Constituyente eran ilegítimos. Además, condenó la violación sistemática de los derechos humanos y las libertades fundamentales, la violencia, la represión y la persecución política, la existencia de presos políticos y la falta de elecciones libres bajo observación internacional independiente. Asimismo, respaldó la decisión de Mercosur de haber aplicado el Protocolo de Ushuaia sobre Compromiso Democrático para suspender a

${ }^{48}$ Andrea Becerril y Víctor Ballinas, "El Congreso exige a Peña respetar los principios de política exterior", La Jornada, 22 de junio de 2017, http://www.jornada.unam.mx/2017/06/22/politica/004n3pol (consultado el 15 de agosto de 2017).

${ }^{49}$ Loc. cit.

${ }^{50}$ Secretaría de Relaciones Exteriores, SRE, "México no reconoce la elección de la Asamblea Nacional Constituyente en Venezuela”, comunicado núm. 295, 30 de julio de 2017, https://www.gob.mx/sre/prensa/ mexico-no-reconoce-la-eleccion-de-la-asamblea-nacional-constituyenteen-venezuela (consultado el 30 de julio de 2017). 
Venezuela de ese mecanismo. ${ }^{51}$ Unos días después, los miembros del Grupo condenaron que la Asamblea Constituyente adoptara de facto competencias de la Asamblea Legislativa.

Los ejemplos examinados en esta sección indican varias cuestiones: la primera, México apoyó el multilateralismo de manera tal que estuvo dispuesto a recurrir a sus mecanismos para tratar temas internos y defendió en la oEA valores considerados universales. Sin embargo, esos valores incidieron directamente en el país, provocando críticas a la política exterior por falta de congruencia con lo que aquí sucede. Además, el caso de Venezuela muestra que lo que sucede en la región provoca más la reacción de la opinión pública que lo que puede proponerse en la onU. Ésta parece un mundo más lejano que da a México mayor libertad de acción y prestigio internacional.

¿Por qué México decidió actuar como lo hizo, invitando al GIEI y promoviendo la democracia en Venezuela? Además del apoyo al multilateralismo por las razones que se han argumentado en este artículo, podrían considerase dos respuestas más. La primera, por representar la continuidad con una política exterior de democracia y derechos humanos iniciada durante la administración de Fox, que pretendía contribuir al respeto de los derechos humanos y al fortalecimiento de la democracia en México; el llamado "efecto candado". La segunda, la congruencia con el objetivo general de política exterior del gobierno de Peña de hacer de México un "actor con responsabilidad global", es decir, un jugador regional. En ambos casos, esa estrategia tuvo costos para la política interna e internacional de México, lo cual es indicativo de que la capacidad de influencia internacional conlleva riesgos.

51 "Cancilleres de 12 países de América y el Caribe suscriben en la 'Declaración de Lima' que Venezuela 'no es una democracia' ”, BBC Mundo, 9 de agosto de 2017, http:/ / www.bbc.com/mundo/40871449 (consultado el 9 de agosto de 2017). 


\section{Conclusiones}

La actividad de México en las organizaciones más representativas a nivel mundial y regional está fuera de discusión. Como bien lo indican los estudiosos del multilateralismo, México procuró influir en el diseño de reglas y normas y, por lo tanto, del comportamiento de los Estados de manera colectiva, para reducir costos y obtener legitimidad y reconocimiento. Hay, sin embargo, dos cuestiones que deben destacarse: 1) la efectividad de México en el ámbito internacional y 2) la congruencia entre política interna y política exterior (y, en consecuencia, la legitimidad de la última). Respecto de la primera, ya se ha mencionado que, a pesar de las gestiones del gobierno en varios temas, los acuerdos logrados no son vinculantes o, si lo son, los países más importantes -según el asunto- pueden no firmarlos ni ratificarlos. Así pues, México contribuye a moldear una gobernanza que puede resultar ineficaz o imperfecta. Dos ejemplos ilustran este argumento: Estados Unidos no es parte del PMм ni del Acuerdo de París y la situación en Venezuela no ha cambiado según las propuestas de México y de la oEA.

En relación con la segunda cuestión, la diplomacia multilateral, al entrar en casa, generó serios cuestionamientos sobre la legitimidad de la política exterior mexicana de democracia y derechos humanos. Lo que el caso del GIEI ilustra es la confianza de las autoridades ante los mecanismos multilaterales, pero con límites. Lo mismo que con la política hacia Venezuela, recurrir a la CIDH terminó por cuestionar la situación en México. Esto no es necesariamente negativo; al contrario, puede ayudar al debate interno sobre dos temas esenciales para la vida política del país, pero tuvo costos. Así pues, hay límites a lo que México puede hacer, aunque no sólo por sus capacidades o debilidades, sino también por el cuestionamiento de algunos países al multilateralismo.

Finalmente, ¿fue México un actor con responsabilidad global o multilateral? Lo que este artículo sugiere es que México ha sido responsable de sus intereses en el ámbito multi- 
lateral pero que su objetivo en materia de política exterior ha sido convertirse más que un actor responsable, en uno influyente.

\section{Bibliografía}

Barbosa Fernández, Ana Paola, "La política exterior de México en las oмP”, México, Secretaría de Marina, Instituto de Investigaciones Estratégicas de la Armada de México, 2015.

Becerril, Andrea y Víctor Ballinas, "El Congreso exige a Peña respetar los principios de política exterior", La Jornada, 22 de junio de 2017, http://www.jornada.unam.mx/2017/06/22/ politica/004n3pol, consultado el 15 de agosto de 2017.

Bull, Hedley, The Anarchical Society. A Study of Order in World Politics, 3a. ed., Londres, Palgrave, 2002.

"Cancilleres de 12 países de América y el Caribe suscriben en la 'Declaración de Lima' que Venezuela 'no es una democracia'”, BBC Mundo, 9 de agosto de 2017, http:/ /www.bbc.com/ mun do/40871449 (consultado el 9 de agosto de 2017).

"Confirma Peña desde Copenhague el fin de la estancia del GIEI en México", La Jornada, 15 de abril de 2016, https://www.jor nada.com.mx/2016/04/15/politica/005n2pol (consultado el 15 de agosto de 2017).

Covarrubias, Ana, "La política de México hacia América Latina en el siglo xxI: ¿congruencia y legitimidad?”, en Estudios Internacionales, vol. 49 (2017), edición especial 50 años.

"Declaración a medios y conferencia de prensa de Cancilleres en la 47 Asamblea General de la OEA", 19 de junio de 2017, https:/ / www.gob.mx/sre/es/prensa/declaracion-a-medios-y-conferen cia-de-prensa-de-cancilleres-en-la-47-asamblea-general-dela-oea?idiom=es (consultado el 2 de noviembre de 2018).

"Declaración de Lima: 'En Venezuela se ha roto el orden democrático' ", 8 de agosto de 2017, http://www.cnnchile.com/noti cia/2017/08/08/declaracion-de-lima-en-venezuela-se-ha-rotoel-orden-democratico (consultada el 19 de agosto de 2017). 
Franco, Marina, "El caso Ayotzinapa: Cuatro años de dolor e incertidumbre", The New York Times, 26 de septiembre de 2018, https:/ /www.nytimes.com/es/2018/09/26/ayotzinapa-estudiantes-43-mexico/ (consultado el 29 de noviembre de 2018). Gómez Mena, Carolina, "Un puñado de gobiernos derechistas busca aislar a Venezuela, afirman académicos", La Jornada, https:/ / www.jornada.com.mx/2017/06/21/politica/004n2pol (consultado el 15 de agosto de 2017).

GrabendorfF, Wolf, "El impacto de la globalización sobre el peso geopolítico del eje transatlántico en el orden internacional”, en Andrés Serbin (ed.), América Latina y el Caribe frente a un Nuevo Orden Mundial: poder, globalización y respuestas regionales, Barcelona y Buenos Aires, Icaria-CRIEs, 2018, pp. 153-168.

Hutschenreuter, Alberto, “¿Crisis del atlantismo y del orden liberal internacional?”, en Andrés Serbin, (ed.), América Latina y el Caribe frente a un Nuevo Orden Mundial: poder, globalización y respuestas regionales, Barcelona y Buenos Aires, Icaria- CRIES, 2018, pp. 169-184.

Keohane, Robert O., "Multilateralism: An Agenda for Research", International Journal, vol. 45, núm. 4 (otoño de 1990), pp. 731-764.

LomónACo, Jorge, "Hacia la prohibición de las armas nucleares", Revista Mexicana de Política Exterior, núm. 10 (mayo-agosto de 2017), pp. 79-95.

Morales Tenorio, G. Isaac, "Estrategia multilateral de México frente al problema de las drogas: del diagnóstico a la acción", Revista Mexicana de Política Exterior, núm. 10 (mayo-agosto de 2017), pp. 135-152.

NÁJAR, Alberto, "México: Expertos del caso Ayotzinapa se despiden y denuncian obstáculos en su investigación", BBC Mundo, 24 de abril de 2016, https://www.bbc.com/mundo/noticias/2016/ 04/160424_ayotzinapa_giei_informe_final_an (consultado el 29 de noviembre de 2018).

Olivares Alonso, Emir, "Lamenta Pérez Esquivel la impunidad en México ante crímenes de lesa humanidad", La Jornada, 15 de abril de 2016, http:/ / www.jornada.unam.mx/2016/04/15/ politica/006n1pol (consultado el 15 de agosto de 2017). 
Peña Nieto, Enrique, "Discurso del Presidente de México, Enrique Peña Nieto, durante la Sesión Especial de la Asamblea General sobre el problema mundial de las drogas (UNGASs) 2016", 19 de abril de 2016, https://www.gob.mx/cms/uploads/attachment/file/210802/7._PEUM-_UNGASS_2016.pdf (consultado el 2 de noviembre de 2018).

Pietrich, Blanche y Georgina Saldierna, "Hoy, nueva embestida contra Maduro encabezada por EU", La Jornada, 19 de junio de 2017, http://www.jornada.unam.mx/2017/06/19/politica/003 n1pol (consultada el 15 de agosto de 2017).

RugGIE, John Gerard, "Multilateralism: the Anatomy of an Institution”, International Organization, vol. 46, núm. 3 (verano de 1992), pp. 561-598.

Ruiz Cabañas Izquierdo, Miguel y María Paulina Rivera Chávez, "En defensa del multilateralismo", Revista Mexicana de Política Exterior, núm. 10 (mayo-agosto de 2017), pp. 9-27.

SAldierna, Georgina y Blanche Pietrich, "Caracas exige en la oEA verdad y justicia para el caso Ayotzinapa”, La Jornada, 21 de junio de 2017, https://www.jornada.com.mx/2017/06/21/ politica/003n1pol (consultado el 15 de agosto de 2017).

Saldierna, Georgina y Blanche Pietrich, "Fracasa golpeteo contra Venezuela", La Jornada, 22 de junio de 2017, http://www. jornada.unam.mx/2017/06/22/politica/002n1pol (consultado el 15 de agosto de 2017).

Secretaría de Relaciones Exteriores, SRE, "México no reconoce la elección de la Asamblea Nacional Constituyente en Venezuela", comunicado núm. 295, 30 de julio de 2017, https://www. gob.mx/sre/prensa/mexico-no-reconoce-la-eleccion-de-laasamblea-nacional-constituyente-en-venezuela (consultado el 30 de julio de 2017).

Secretaría de Relaciones Exteriores, SRE, "Situación en Venezuela", comunicado núm. 252, https//www.gob.mx/sre/prensa/situa ción-en-venezuela?idiom=es (consultado el 31 de julio de 2017).

Secretaría de Relaciones Exteriores (SRE), Embajada de México en Santa Sede, "México reafirma su compromiso con el multilateralismo y con la gobernanza efectiva de la migración internacional" (comunicado de prensa), 13 de julio de 2018, https:// 
embamex.sre.gob.mx/vaticano/index.php/noticias/256mexico-en-el-pacto-mundial-para-una-migracion-segura-orde nada-y-regular (consultado el 2 de noviembre de 2018).

TAGO, Atsushi, "Multilateralism, Bilateralism, and Unilateralism in Foreign Policy", Oxford Research Encyclopedia of Politics, doi: 10.1093/acrefore/9780190228637.013.449.

Urrutia, Alonso, Georgina Saldierna y Blanche Petrich, "Multilateralismo, el camino: Peña”, La Jornada, 20 de junio de 2017, http://www.jornada.unam.mx/2017/06/20/politica/004n1 pol (consultado el 15 de agosto de 2017).

Videgaray, Luis, "Conferencia de prensa por la clausura del 47 Periodo Ordinario de Sesiones de la AEA", 21 de junio de 2017, https://www.gob.mx/sre/prensa/mensaje-del-cancillerluis-videgaray-en-la-conferencia-de-prensa-por-la-clausura-del47-periodo-ordinario-de-sesiones-de-la-agoea (consultado el 2 de noviembre de 2018).

Washington Office on Latin America, wola, "Un año después de la salida del GIEI de México: el caso de Ayotzinapa sigue sin resolverse y las desapariciones en México se mantienen en niveles preocupantes", 21 de abril de 2017, https://www.wola. org/es/analisis/un-ano-despues-de-la-salida-del-giei-de-mexi co-el-caso-de-aytozinapa-sigue-sin-resolverse-y-las-desaparicio nes-en-mexico-se-mantienen-en-niveles-preocupantes/

\section{Instrumentos jurídicos, informes y reportes}

Acuerdo para la incorporación de asistencia técnica internacional desde la perspectiva de los derechos humanos en la investigación de la desaparición forzada de 43 estudiantes de la normal rural Raúl Isidro Burgos de Ayotzinapa, Guerrero, dentro de las medidas cautelares MC/409/14 y en el marco de las facultades de monitoreo que la ciDH ejerce sobre la situación de los derechos humanos en la región, en Centro Prodh (sitio de internet), centroprodh.org.mx/GIEI/?page_id=19

Secretaría de Relaciones Exteriores, SRE, Cuarto Informe de Labores 2015-2016. 
FI LIX-3-4 MéXico: ¿ACTOR CON RESPONSABILIDAd MUltilateral? 669

Secretaría de Relaciones Exteriores, SRE, Sexto Informe de Labores 2017-2018.

Secretaría de Relaciones Exteriores, SRE, Tercer Informe de Labores 2014-2015.

Videgaray Caso, Luis, "Presentación", Sexto Informe de Labores 2017-2018, México, Secretaría de Relaciones Exteriores, 2018. 
